\title{
Prevalence of Nutritional Stunting and Associated Risk Factors among Under Five Children in Suhag Governorate
}

\author{
Amira N. Shaban, Hoda D. Fahmy \& Asmaa K. Hassan. \\ Nursing Specialist in Suhag Health Directorate, Egypt. \\ Professor of Community Health Nursing, Faculty of Nursing, Assiut University, Egypt. \\ Lecturer of Community Health Nursing, Faculty of Nursing, Assiut University, Egypt.
}

\begin{abstract}
Introduction : Nutritional stunting indicates the chronic restriction of a child potential growth, Aim: To assess the prevalence and associated risk factors affecting nutritional stunting among children under five years at Suhag Governorate. Methods: This study had been conducted at Suhag Governorate. The total number of the sample 1268 children who recruited through convenient sample. Results: Slightly less than half $(49.1 \%)$ of the children were aged und 2 years. $53 \%$ of them were boys and $47 \%$ were girls.. According to nutritional assessment of children under five years. It was noticed that $23.6 \%$ of them had moderate stunting and $11.3 \%$ of them had severe stunting while $15.6 \%$ of them had moderate underweight, $7.7 \%$ of them had severe underweight. Conclusion: More than one third of the studied children were stunted with chronic malnutrition also their mothers had unsatisfactory knowledge about nutritional stunting. Recommendations: Increase awareness of mothers about nutritional stunting, monitoring growth and development of their children, also educational program should be given for mothers of stunting children about nutrition, also small guideline book for mothers with stunting children to improve knowledge practice and attitude toward their children.
\end{abstract}

\section{Keywords: Nutrition, Stunting, Preschool Children \& Suhag Governorate Egypt.}

\section{Introduction}

Malnutrition continues to be significant public health and development concern around the world. With about one - third of the world's children are malnourished. The three main indicators used to define under nutrition, i.e., stunting, underweight and wasting! that represent different histories of nutritional insult to the child and measured by height for age, weight for height and weight for age indexes respectively. Stunting is a measure of chronic malnutrition ( De Onis et al., 2010 ).

Nutritional stunting is a primary manifestation of malnutrition in early childhood caused by inadequate food intake and infections during the period that begins in utero and continues through child first years of life. (Victoria et al., 2010 )

Worldwide 161 million children under age 5 are too short for their age ( stunted ) 51 million don't weight enough for their height ( wasted ), while 42 million are overweight : none of these children are growing healthness , more than $90 \%$ of the world's stunted children live in Africa and Asia, where respectively $40 \%$ and $36 \%$ of children are affected ( UNCIEF / WHO / World Bank, United Nations Children's Fund 2015).

Egypt - demographic and health survey indicates that there is a considerable rate of stunting among Egyptian children $29 \%$ of children under 5 years of age were stunting and $14 \%$ were severely stunted. The prevalence of stunting was higher in rural area
$30 \%$, VS urban $27 \%$ and the prevalence of sever stunting is the same in both urban and rural about $14 \%$. The progress of stunting has been highly prevalence in the world (nutritional status of the Egyptian population in Egypt, 2010)

Infant and young child feeding practices that contribute to stunting include suboptimal breast feeding (late initiation, non-exclusive breast feeding and early cessation) and inadequate complementary feeding (provision of low quality and /or unsafe foods) . severe infectious diseases lead to wasting, which may have long-term consequences on linear growth depending on severity duration and recurrence particularly if there is insufficient food or inappropriate feeding practices to support recovery (Teshome, 2013)

Community health nurses as a health care provider had an important roles in stunting reduction to improve maternal nutrition and health, beginning with adolescent girls to educate and empower future mothers to make a good economic and health choices for themselves and their children about maternity protection (pre- and postnatal care). Protect and promote exclusive breast feeding in the first six months to provide "secure" nutrition and protect infants from gastrointestinal infections. Promote consumption of healthy, diversified diets including high-quality, nutrient rich foods in the complementary feeding period six to $\mathbf{2 3}$ months (WHO, 2013) 


\section{Aim of the study}

To assess the prevalence and associated risk factors affecting nutritional stunting among children under five years in Suhag Governorate.

\section{Research Question}

Is the prevalence of nutritional stunting among children under five years at suhag governorate high?

\section{Significance of the study}

One of every three Egyptian children under 5 years old stunted, ranking Egypt among the 34 countries with the highest burden of malnutrition-where $90 \%$ the word's stunted children reside. Stunted Egyptian children are more likely to repeat grade and drop out school, according to modeled estimates of 2009 data

(Black et al., 2013). The cost of hunger in Africa Egypt study also estimated losses of (857) million working hours among stunted adults (Egyptian cabinet information and decision support center (IDSC), 2013)

\section{Subjects \& Methods}

- Study design

Descriptive study design was carried out used in this research.

\section{- Study setting}

The present study had been carried out in Suhag Governorate it is located in the southern part of the country (Upper Egypt) and covers a stretch of the Nile Valley. Since 1960, the capital has been the city of Suhag Total area of Suhag governorate is (1.547 $\mathrm{Km} 2)$ total population $(4,469151)$. Density is 2900 km2 .Suhag Governorate consists of (11) distract. At North (Tema, Tahta, Al Maraghaa), At west (Guhanya). At East (Dar AlSalam, Saqulta, Akhmim), At South Suhag (Al Menshaa, Gerga, Al Balyana) and Suhag city.From each district select one city and two villages which selected randomly.

This study conducted in (17) nursery school, (5) Maternal child health centers and (10) Rural health units which represents (10\%) from total number of nursery school, Maternal child health centers and Nursery schools from each district in Suhag governorate to collect necessary data.

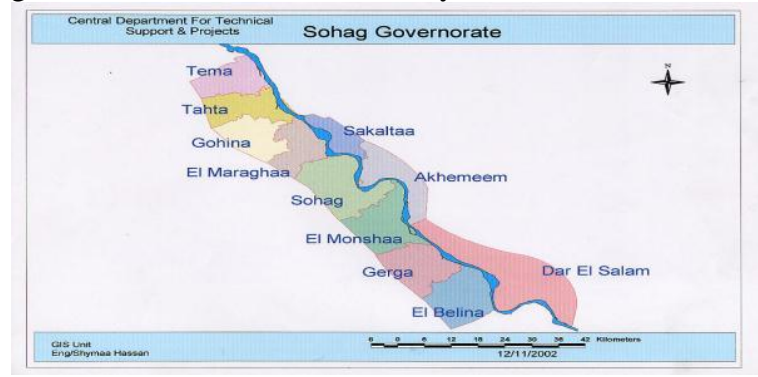

Suhag Governorate map.

\section{Sample}

Convenient sample, total coverage of children in all selected setting. the total number were 1268 child as well as 1268 their mother's .

\section{Inclusion criteria}

All children under five years who were free from any medical disease or disabilities.

\section{Tools of the study}

An interview questionnaire sheet was prepared by the researcher for the collection of data it was developed after reviewing of relevant literature which divided into five parts.

Part (I):It included sociodemographic characteristics of the study participants as (age, sex of child, mother's age, educational level, marital status and occupation, Residence, economic status.

Part (II):It included measurements that include height, weight as well as body mass index of child to assess the degree of stunting anthropometric data were obtained by measuring weight of child by using specific scale for infants and early childhood age group. Child was with minimum clothing and no shoes and in recumbent or sitting position of this scale without any support of child and read weight to the nearest kilo grams.

The child length was measured by non-stretchable tap as the following:

- Child lies in recumbent position on stiff or hand surface.

- Hold child head then fully extended the child leg.

- Put a no stretchable tap a long side child body extending from crown of the child head to the heel of the child foot and then read length measurement in centimeters. Converted these measurement to weight for age, length

- for age and weight for length using who standard growth charts of weight for age, length for age and weight for length of boys and girls specific for this age group the other 2006 of software of the WHO was used to calculating the $\mathrm{z}$-score to assess the degree of stunting. Calculate (body mass index= weight / height ${ }^{2}$ )

Part (III): it included questions to assess Mother's knowledge regarding nutritional stunting such as definition of nutritional stunting, causes, signs and symptoms, predisposing factors.... etc.

Part (IV):Included health status of the child complains.

Part (V): That included assessment of mother's knowledge regarding child feeding practice and general rules that followed it during weaning such as: quality of feeding child, breast feeding, initiation, duration the time of child weaning, storage and safe preparation of weaning food, nutrition during and after period of child illness 
Total score of knowledge were (64) using scoring system for knowledge, a correct response was scored (1) grade and zero for the incorrect. The score of knowledge each item summed-up and then converted into a percent score (Unsatisfactory $=$ score $<50 \%$, satisfactory score $50 \%$ and more). (Elshafy et al., 2013).

\section{Preparatory phase}

An official letter approval was obtained from the Dean of faculty of Nursing Assuit university to the first undersecretary of the ministry of health as a permission to carry out the study at maternal, child health centers, rural health units and an official letter to the first undersecretary of the ministry of social affairs as a permission to carry out the study at Nursery school at Suhag governorate.

\section{Pilot study}

It was carried out before starting data collection, in the 10\%(126) which included in the sample it is aimed to test the clarity of the tool and to estimate the time required to fill questionnaire based on the result of the pilot study.

\section{Field work}

The researcher started to collect data from the first of march 2015 until the end of November 2015 (9 months).

Mothers were personally interviewed to obtain information on socio demographic data, health condition, nutrition related issues and child related data as age, birth weight and other characteristics relating to wealth.

At nursery school the researchers met the mothers when she came to take their children and through meeting and home visit by did appointment interview with mother in the home when mothers didn't came to take their child I take phone number from medical file's child and contact with her, met mother during immunization of her child at $(\mathrm{MCH} \&$ Rural Health Units).

Each interview form took about $(20: 30)$ minutes and every answer from mother was recreated according designed question form followed by correction explanation for every wrong answer and distribution pursuer about how to protect and promote child health from nutritional stunting.Data were collected 4 days/week. Every week about $(32-36)$ sheets about (9) sheet daily were finished.

\section{Statistical analysis}

The data obtained were reviewed, prepared for computer entry, coded, analyzed and tabulated using excel 2010. Descriptive statistics (i.e., frequencies and mean, standard deviation, etc.) was done using computer program SPSS version 19. Chi-square test used to compare differences in the distribution of frequencies among different groups. It is considered * significant when P-values were less than 0.05.

\section{Ethical considerations}

Research proposal was approved from Ethical Committee in the Faculty of Nursing. There is no risk for study subject during application of the research. The study was following common ethical principles in clinical research.

Confidentiality and anonymity will be assured. Mothers have the right to refuse to participate andlor withdraw from the study without any rational . 


\section{Results}

Table (1): Distribution of the study sample regarding to their socio-demographic characteristics. $(\mathrm{N}=1268)$.

\begin{tabular}{|c|c|c|}
\hline Socio-demographic characteristics for child & No. $(n=1268)$ & $\%$ \\
\hline \multicolumn{3}{|l|}{ Age of the child } \\
\hline$<2$ years & 622 & 49.0 \\
\hline $2-<4$ years & 426 & 33.6 \\
\hline$\geq 4$ years & 220 & 17.4 \\
\hline \multicolumn{3}{|l|}{ Sex } \\
\hline Boy & 678 & 53.5 \\
\hline Girl & 590 & 46.5 \\
\hline \multicolumn{3}{|l|}{ Residence } \\
\hline Rural & 634 & 50.0 \\
\hline Urban & 634 & 50.0 \\
\hline \multicolumn{3}{|l|}{ Birth order } \\
\hline First & 351 & 27.7 \\
\hline Second & 401 & 31.6 \\
\hline Third & 314 & 24.8 \\
\hline Fourth or more & 202 & 15.9 \\
\hline \multicolumn{3}{|l|}{ Preceding birth interval } \\
\hline$<24$ months & 457 & 42.5 \\
\hline $24-<48$ months & 514 & 47.8 \\
\hline$\geq 48$ months & 104 & 9.7 \\
\hline \multicolumn{3}{|l|}{ Socio demographic characteristics For mother } \\
\hline \multicolumn{3}{|l|}{ Mother age } \\
\hline$<25$ years & 295 & 23.2 \\
\hline $25-<35$ years & 739 & 58.3 \\
\hline$\geq 35$ years & 234 & 18.5 \\
\hline \multicolumn{3}{|l|}{ Mother age at delivery } \\
\hline$<25$ years & 449 & 35.4 \\
\hline $25-<35$ years & 736 & 58.1 \\
\hline$\geq 35$ years & 83 & 6.5 \\
\hline \multicolumn{3}{|l|}{ Mother education } \\
\hline Illiterate & 215 & 17.0 \\
\hline Read and write & 105 & 8.2 \\
\hline Primary & 86 & 6.8 \\
\hline Preparatory & 162 & 12.8 \\
\hline Secondary & 497 & 39.2 \\
\hline University & 203 & 16.0 \\
\hline \multicolumn{3}{|l|}{ Mother occupation } \\
\hline Employee & 231 & 18.2 \\
\hline Skilled & 48 & 3.8 \\
\hline Housewife & 989 & 78.0 \\
\hline
\end{tabular}


Table (2): The relationship between level of mothers knowledge and their socio-demographic characteristics .(N=1268).

\begin{tabular}{|c|c|c|c|c|c|c|}
\hline \multirow{3}{*}{ Variables } & \multicolumn{4}{|c|}{ Level of knowledge } & \multirow{3}{*}{$\mathbf{X}^{2}$} & \multirow{3}{*}{ P-value } \\
\hline & \multicolumn{2}{|c|}{$\begin{array}{c}\text { Unsatisfactory } \\
(n=1161) 91.6 \%\end{array}$} & \multicolumn{2}{|c|}{$\begin{array}{c}\text { Satisfactory } \\
(n=107) 8.4 \%\end{array}$} & & \\
\hline & No. & $\%$ & No. & $\%$ & & \\
\hline \multicolumn{5}{|l|}{ Residence } & \multirow{3}{*}{37.98} & \multirow{3}{*}{$0.000 *$} \\
\hline Rural & 611 & 96.4 & 23 & 3.6 & & \\
\hline Urban & 550 & 86.8 & 84 & 13.2 & & \\
\hline \multicolumn{5}{|l|}{ Mother education } & \multirow{7}{*}{74.67} & \multirow{7}{*}{$0.000^{*}$} \\
\hline Illiterate & 211 & 98.1 & 4 & 1.9 & & \\
\hline Read and write & 103 & 98.1 & 2 & 1.9 & & \\
\hline Primary & 83 & 96.5 & 3 & 3.5 & & \\
\hline Preparatory & 160 & 98.8 & 2 & 1.2 & & \\
\hline Secondary & 443 & 89.1 & 54 & 10.9 & & \\
\hline University & 161 & 79.3 & 42 & 20.7 & & \\
\hline \multicolumn{5}{|l|}{ Mother age } & \multirow{4}{*}{8.13} & \multirow{4}{*}{$0.017 *$} \\
\hline$<25$ years & 269 & 91.2 & 26 & 8.8 & & \\
\hline $25-<35$ years & 688 & 93.1 & 51 & 6.9 & & \\
\hline$\geq 35$ years & 204 & 87.2 & 30 & 12.8 & & \\
\hline \multicolumn{5}{|l|}{ Mother occupation } & \multirow{4}{*}{41.75} & \multirow{4}{*}{$0.000^{*}$} \\
\hline Employee & 189 & 81.8 & 42 & 18.2 & & \\
\hline Skilled & 40 & 83.3 & 8 & 16.7 & & \\
\hline Housewife & 932 & 94.2 & 57 & 5.8 & & \\
\hline \multicolumn{5}{|c|}{ Average monthly income } & \multirow{4}{*}{6.01} & \multirow{4}{*}{$0.050 *$} \\
\hline$<1000 \mathrm{LE}$ & 428 & 93.2 & 31 & 6.8 & & \\
\hline 1000-1500 LE & 433 & 92.1 & 37 & 7.9 & & \\
\hline$>1500 \mathrm{LE}$ & 300 & 88.5 & 39 & 11.5 & & \\
\hline
\end{tabular}

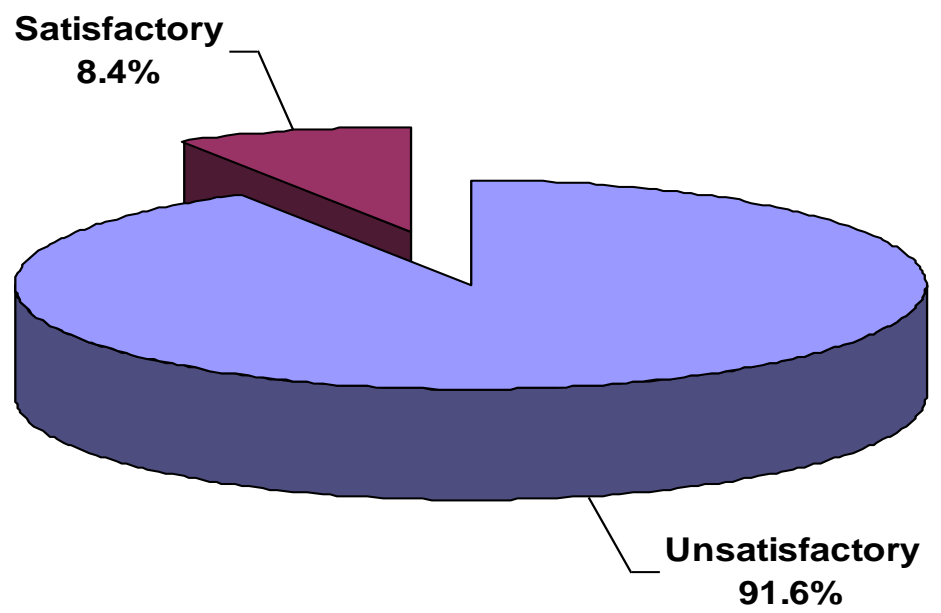

Figure (1): knowledge of mothers about nutritional stunting. 
Table (3): The relationship between the degree of stunting and the safe steps preparation of weaning food . $(\mathrm{N}=1268)$.

\begin{tabular}{|c|c|c|c|c|c|c|c|c|}
\hline & \multicolumn{6}{|c|}{ Degree of stunting } & \multirow{3}{*}{$X^{2}$} & \multirow{3}{*}{ P-value } \\
\hline & \multicolumn{2}{|c|}{$\begin{array}{l}\text { Normal } \\
(\mathrm{n}=\mathbf{8 2 5})\end{array}$} & \multicolumn{2}{|c|}{$\begin{array}{c}\text { Moderate } \\
(n=299)\end{array}$} & \multicolumn{2}{|c|}{$\begin{array}{c}\text { Severe } \\
(n=144)\end{array}$} & & \\
\hline & No. & $\%$ & No. & $\%$ & No. & $\%$ & & \\
\hline $\begin{array}{l}\text { Not wash breast before } \\
\text { breastfeeding }\end{array}$ & 580 & 70.3 & 201 & 67.2 & 95 & 66.0 & 1.71 & 0.425 \\
\hline $\begin{array}{l}\text { Washing hands before preparation } \\
\text { of baby food }\end{array}$ & 759 & 92.0 & 273 & 91.3 & 135 & 93.8 & 0.80 & 0.671 \\
\hline $\begin{array}{l}\text { Wash fruits and vegetables clean } \\
\text { under running water }\end{array}$ & 784 & 95.0 & 286 & 95.7 & 141 & 97.9 & 2.40 & 0.301 \\
\hline $\begin{array}{l}\text { Use clean spoons, cups and dishes } \\
\text { clean before preparation food }\end{array}$ & 775 & 93.9 & 279 & 93.3 & 137 & 95.1 & 0.57 & 0.752 \\
\hline $\begin{array}{l}\text { When you prepare the meal } \\
\text { prepare sufficient amount and only } \\
\text { for one meal }\end{array}$ & 399 & 48.4 & 140 & 46.8 & 63 & 43.8 & 1.11 & 0.573 \\
\hline $\begin{array}{l}\text { Provision of food immediately after } \\
\text { processing }\end{array}$ & 503 & 61.0 & 163 & 54.5 & 83 & 57.6 & 3.92 & 0.141 \\
\hline $\begin{array}{l}\text { Heating meals for the child and } \\
\text { reoffer for baby }\end{array}$ & 630 & 76.4 & 219 & 73.2 & 111 & 77.1 & 1.33 & 0.515 \\
\hline $\begin{array}{l}\text { Avoid using bottle to give the child } \\
\text { any drink }\end{array}$ & 526 & 63.8 & 200 & 66.9 & 86 & 59.7 & 2.25 & 0.325 \\
\hline $\begin{array}{l}\text { Place for food preparation far from } \\
\text { insects, birds, animals }\end{array}$ & 806 & 97.7 & 292 & 97.7 & 142 & 98.6 & 0.51 & 0.776 \\
\hline
\end{tabular}

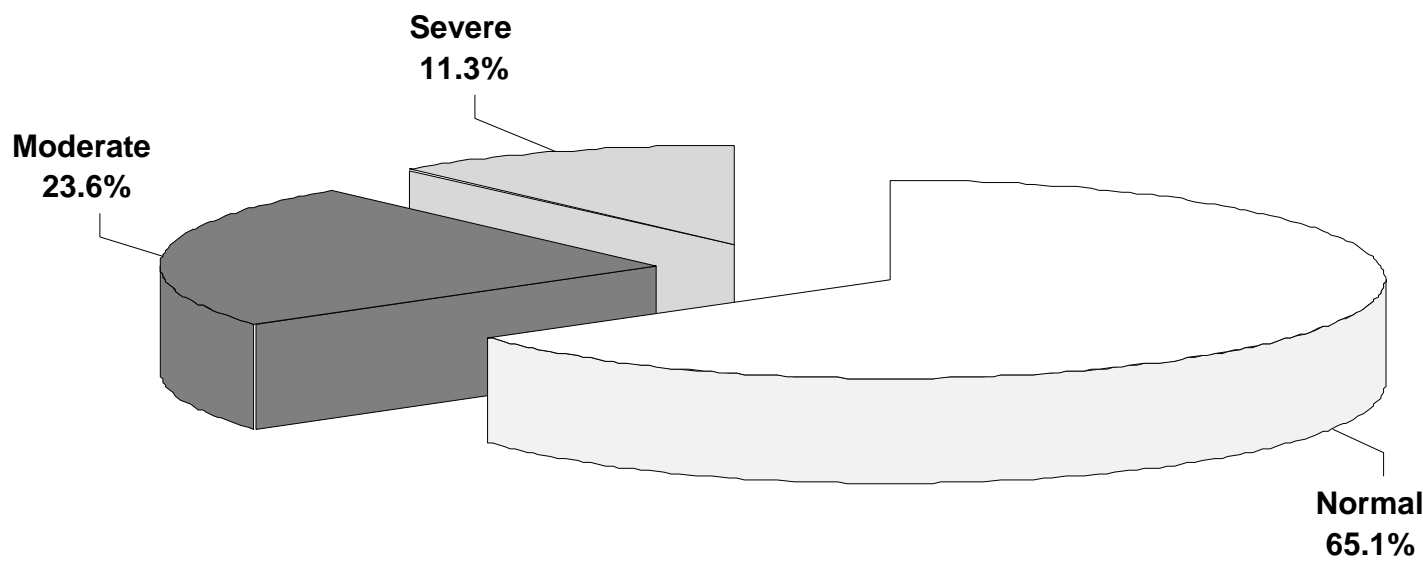

Figure (2) degree of nutritional stunting according to nutritional assessment of the studied children. 
Table (4): The relationship between stunting status and techniques of weaning followed by mothers in Suhag Governorate, 2015. ( $\mathrm{N}=1268$ ).

\begin{tabular}{|c|c|c|c|c|c|c|c|c|}
\hline \multirow{3}{*}{ Variables } & \multicolumn{6}{|c|}{ Degree of stunting } & \multirow{3}{*}{$\mathbf{X}^{2}$} & \multirow{3}{*}{ P-value } \\
\hline & \multicolumn{2}{|c|}{$\begin{array}{r}\text { Normal } \\
(n=825)\end{array}$} & \multicolumn{2}{|c|}{$\begin{array}{c}\text { Moderate } \\
(\mathrm{n}=299)\end{array}$} & \multicolumn{2}{|c|}{$\begin{array}{c}\text { Severe } \\
(n=144)\end{array}$} & & \\
\hline & No. & $\%$ & No. & $\%$ & No. & $\%$ & & \\
\hline $\begin{array}{l}\text { Give small spoon to him/her and } \\
\text { then two or three spoon to reach to } \\
\text { the appropriate quantity of the age } \\
\text { of the child }\end{array}$ & 689 & 83.5 & 245 & 81.9 & 113 & 78.5 & 2.28 & 0.321 \\
\hline $\begin{array}{l}\text { Provide new kinds of food at one } \\
\text { time }\end{array}$ & 525 & 63.6 & 178 & 59.5 & 79 & 54.9 & 4.75 & 0.093 \\
\hline $\begin{array}{l}\text { Not separate } 15 \text { days between any } \\
\text { two new types }\end{array}$ & 363 & 44.0 & 90 & 30.1 & 54 & 37.5 & 18.09 & $0.000 *$ \\
\hline $\begin{array}{l}\text { Provide new food and child } \\
\text { psychologically prepared and not } \\
\text { sick }\end{array}$ & 616 & 74.7 & 239 & 79.9 & 113 & 78.5 & 3.78 & 0.151 \\
\hline $\begin{array}{l}\text { Provision of food before breast } \\
\text { feeding a hungry when even } \\
\text { palatable }\end{array}$ & 625 & 75.8 & 233 & 77.9 & 110 & 76.4 & 0.57 & 0.751 \\
\hline $\begin{array}{l}\text { Begin with the liquid food and soft } \\
\text { than thickness mainstay }\end{array}$ & 727 & 88.1 & 274 & 91.6 & 123 & 85.4 & 4.38 & 0.112 \\
\hline $\begin{array}{l}\text { Give the child some water between } \\
\text { and after meals }\end{array}$ & 712 & 86.3 & 264 & 88.3 & 127 & 88.2 & 0.98 & 0.613 \\
\hline $\begin{array}{l}\text { Continue breastfeeding on demand } \\
\text { and even during the night }\end{array}$ & 666 & 80.7 & 251 & 83.9 & 124 & 86.1 & 3.33 & 0.189 \\
\hline Added iodized salt to food & 626 & 75.9 & 228 & 76.3 & 102 & 70.8 & 1.84 & 0.399 \\
\hline $\begin{array}{l}\text { Giving the child drinks (such as } \\
\text { tea, soft drinks) }\end{array}$ & 455 & 55.2 & 130 & 43.5 & 74 & 51.4 & 12.00 & $0.002 *$ \\
\hline $\begin{array}{l}\text { Giving the child processed junk } \\
\text { foods (such as potato chips Karate) }\end{array}$ & 416 & 50.4 & 110 & 36.8 & 65 & 45.1 & 16.54 & $0.000 *$ \\
\hline
\end{tabular}

Table (5): The relationship between sociodemographic characteristics of child and Stunting status in Suhag Governorate, 2015. $(\mathrm{N}=1268)$.

\begin{tabular}{|c|c|c|c|c|c|c|c|c|}
\hline \multirow{3}{*}{ Variables } & \multicolumn{6}{|c|}{ Stunting status } & \multirow{3}{*}{$\mathbf{X}^{2}$} & \multirow{3}{*}{ P-value } \\
\hline & \multicolumn{2}{|c|}{$\begin{array}{l}\text { Normal } \\
(n=825)\end{array}$} & \multicolumn{2}{|c|}{$\begin{array}{c}\text { Moderate } \\
(n=299)\end{array}$} & \multicolumn{2}{|c|}{$\begin{array}{c}\text { Severe } \\
(n=144)\end{array}$} & & \\
\hline & No. & $\%$ & No. & $\%$ & No. & $\%$ & & \\
\hline \multicolumn{7}{|l|}{ Sex } & \multirow{3}{*}{0.08} & \multirow{3}{*}{0.961} \\
\hline Boy & 442 & 65.2 & 158 & 23.3 & 78 & 11.5 & & \\
\hline Girl & 383 & 64.9 & 141 & 23.9 & 66 & 11.2 & & \\
\hline \multicolumn{7}{|l|}{ Age of the child( years) } & \multirow{4}{*}{94.25} & \multirow{4}{*}{$0.000 *$} \\
\hline$<2$ & 346 & 55.6 & 160 & 25.7 & 116 & 18.6 & & \\
\hline $2-<4$ & 335 & 78.6 & 70 & 16.4 & 21 & 4.9 & & \\
\hline$>4$ & 144 & 65.5 & 69 & 31.4 & 7 & 3.2 & & \\
\hline \multicolumn{7}{|l|}{ Residence } & \multirow{3}{*}{93.89} & \multirow{3}{*}{$0.000 *$} \\
\hline Rural & 349 & 55.0 & 162 & 25.6 & 123 & 19.4 & & \\
\hline Urban & 476 & 75.1 & 137 & 21.6 & 21 & 3.3 & & \\
\hline \multicolumn{7}{|l|}{ Birth order } & \multirow{3}{*}{7.83} & \multirow{3}{*}{0.251} \\
\hline First & 230 & 65.5 & 87 & 24.8 & 34 & 9.7 & & \\
\hline Second & 258 & 64.3 & 98 & 24.4 & 45 & 11.2 & & \\
\hline
\end{tabular}




\begin{tabular}{|c|c|c|c|c|c|c|c|c|}
\hline \multirow{3}{*}{ Variables } & \multicolumn{6}{|c|}{ Stunting status } & \multirow{5}{*}{$\mathbf{X}^{2}$} & \multirow{5}{*}{ P-value } \\
\hline & \multicolumn{2}{|c|}{$\begin{array}{l}\text { Normal } \\
(n=825)\end{array}$} & \multicolumn{2}{|c|}{$\begin{array}{l}\text { Moderate } \\
(n=299)\end{array}$} & \multicolumn{2}{|c|}{$\begin{array}{c}\text { Severe } \\
(n=144)\end{array}$} & & \\
\hline & No. & $\%$ & No. & $\%$ & No. & $\%$ & & \\
\hline Third & 217 & 69.1 & 63 & 20.1 & 34 & 10.8 & & \\
\hline Fourth or more & 120 & 59.4 & 51 & 25.2 & 31 & 15.3 & & \\
\hline \multicolumn{7}{|c|}{ Preceding birth interval (months) } & \multirow{4}{*}{11.16} & \multirow{4}{*}{$0.025 *$} \\
\hline$<24$ & 302 & 66.1 & 96 & 21.0 & 59 & 12.9 & & \\
\hline $24-<48$ & 336 & 65.4 & 137 & 26.7 & 41 & 8.0 & & \\
\hline$\geq 48$ & 71 & 68.3 & 19 & 18.3 & 14 & 13.5 & & \\
\hline
\end{tabular}

Table (6): The relationship between stunting status and nutritional status during and after periods of illness. in Suhag Governorate, 2015. $(\mathrm{N}=1268)$.

\begin{tabular}{|c|c|c|c|c|c|c|c|c|}
\hline \multirow{3}{*}{ Variables } & \multicolumn{6}{|c|}{ Stunting status } & \multirow{3}{*}{$\mathbf{X}^{2}$} & \multirow{3}{*}{ P-value } \\
\hline & \multicolumn{2}{|c|}{$\begin{array}{l}\text { Normal } \\
(n=825)\end{array}$} & \multicolumn{2}{|c|}{$\begin{array}{c}\text { Moderate } \\
(n=299)\end{array}$} & \multicolumn{2}{|c|}{$\begin{array}{c}\text { Severe } \\
(n=144)\end{array}$} & & \\
\hline & No. & $\%$ & No. & $\%$ & No. & $\%$ & & \\
\hline $\begin{array}{l}\text { Not increasing the amount of fluid } \\
\text { during illness }\end{array}$ & 639 & 77.5 & 207 & 69.2 & 110 & 76.4 & 8.09 & $0.018 *$ \\
\hline Continue breastfeeding & 664 & 80.5 & 257 & 86.0 & 122 & 84.7 & 5.17 & 0.075 \\
\hline $\begin{array}{l}\text { Disencourage your child to eat during } \\
\text { period of illness }\end{array}$ & 697 & 84.5 & 210 & 70.2 & 101 & 70.1 & 36.07 & $0.000 *$ \\
\hline $\begin{array}{l}\text { Not give extra meals in the recovery } \\
\text { period until the child regains his } \\
\text { health and continues to grow }\end{array}$ & 642 & 77.8 & 196 & 65.6 & 99 & 68.8 & 19.35 & $0.000 *$ \\
\hline
\end{tabular}

Table (1): This table shows distribution of the study sample regarding to their socio-demographic characteristics, it was noticed that slightly less than half $(49.1 \%)$ of the children were aged under 2 years. More than half $(53 \%)$ of the children were boys and $47 \%$ were girls, more than half $(58 \%)$ of mothers aged 25: 35 years old. More than one third (35.4\%) of the mothers were in the age at delivery less than 25 years. and only $6.5 \%$ of them were more than 35 years old. While preceding birth interval only $9.7 \%$ of mothers the birth interval more than 48 months. On the other hand, $39.0 \%$ of the mothers had secondary education level while $6.8 \%$ of them had primary education level.

Table (2): This table shows the relation between level of knowledge and mothers personal characteristics It reveals that there is a significant difference between level of knowledge about nutritional stunting and all mothers' personal characteristics $(\mathrm{P}=0,000, \mathrm{P}=0.000, \mathrm{P}=0.017, \mathrm{P}=0.000$ and $\mathrm{P}=0.050$ ) respectively.

Figure (1): This figure revealed that vast majority $(91.6 \%)$ of mothers had unsatisfactory knowledge about nutritional stunting while only $8.4 \%$ had satisfactory knowledge about it.
Table (3): This table shows the relation between safe preparation of weaning food and degree of stunting. It reveals that there is no significant difference between degree of stunting and safe preparation of weaning food in all items.

Figure (2): This figure represented that $65.1 \%$ had normal length and $23.6 \%$ of them had moderate stunting while $11.3 \%$ had severe stunting

Table (4): This table shows the relation between rules during weaning and degree of stunting. It reveals that there is a significant difference between degree of stunting, giving the child drinks (such as tea, soft drinks)and Giving the child processed and junk foods (such as potato, chips, Karate and not separate 15 days between any two new types $(\mathrm{P}=0.002, \mathrm{P}=0.000$ and $\mathrm{P}=0.000)$ respectively .

Table (5): This table shows the relation between nutrition during and after periods of illness and degree of stunting. It reveals that there is a significant difference between degree of stunting and discourage child to eat during period of illness, not give extra meals in the recovery period until the child regains his health and continues to grow. $(\mathrm{P}=0.000, \mathrm{P}=0.000)$ respectively .

Table (6): This table shows the relation between degree of stunting and child characteristics. It reveals that there is a significant difference between degree 
of stunting and age of the child, residence and Preceding birth interval $\mathrm{P}=0.000, \mathrm{P}=0.000$ and $\mathrm{P}=0.025$ respectively.

Regarding the relation between the sex of child and the degree of stunting it was clear that there is no significant difference $(\mathrm{p}=0.961)$.Also there no significant difference between the birth order of child and the degree of stunting $(\mathrm{p}=0.251)$.

\section{Discussion}

Stunting is a predictor of risk as it reflects the overall level of development characterized by poverty, low socioeconomic status, and the prevalence of chronic diseases. Nutritional status is related to physical, mental, social and intellectual growth, beginning with fetal development, infancy, and childhood and extending to adolescence and adulthood (Rahman \& chudhury, 2007).

The findings of the present study showed that a high proportion of children were stunted $34.9 \%$, similar findings $35.0 \%$, were reported by Kikafunda et al., (2010) in a study conducted among children under five years of age in Uganda .

The present findings of no significant association between mother's education and mother's occupation and height for age were similar to Deshmukh et al., (2013) who observed that mother's education and occupation did not contribute significantly to the stunting •

In this study, the residence was positively associated with the nutritional status of children. It was observed significant difference $(\mathrm{P}$ value $=0.000 *$ ) in rural and urban area $(44.3 \%)$ and $(24.9 \%)$ respectively. This was in coherence with Mahfouz et al., (2003) who found that stunting was significantly higher in rural area in comparison to urban area.( Mahfouz et al., 2003), this finding might be due to lack family awareness about food diversity, early marriage of girl and sanitation facilities.

The finding of this study showed that a degree of stunting was significantly more among children under two years where opposite to study, in Ghana (Rathavuth \& Vinod 2006). They indicated that older children had a higher prevalence of stunting than younger children and similar to study conducted in Peru indicated that the level of stunting increases with among children under two years (Food \& Agriculture Organization, FAO, 2008), This might be due to stunting in children aged 24 months were resulted from poor nutritional status of mothers at pregnancy, inappropriate infant and young child feeding practices.

Regarding to the relation between degree of nutritional stunting and underweight it was observed that a significant association between degree of stunting and underweight was in agreement with the observation of Jesmin et al., (2011).

As regards birth interval of child the finding in this study show was significant difference between birth interval and degree of stunting $\quad(\mathrm{P}$ value $=$ $0.025 *)$ this result agrees with Egypt demographic and health survey (EDHS), 2011) who reported that, there is an inverse relationship between the length of the preceding birth interval and the proportion of children who are stunted (Central Statistical Agency [Ethiopia] 2011).

In the current study was observed that no significant difference in prevalence of stunting by sex of the child. These results agreed with studies conducted in Cambodia (Peiris \& widisingle, 2010) and in Ethiopia (Happiness, 2010) In contrast, the results in secondary data analysis in Sub Saharan - Africa confirmed that the prevalence of stunting was higher among boys compared to girls (Teshome, 2009). This might be due to our families not differentiated in offering food among boys and girls.

Birth order of children is one of the demographic variables explaining the risk of stunting in children. Children of 4 and above birth order were more likely to be stunted than children of first birth order. The finding of the present study was estimated that $40.5 \%$ for birth order fourth or more vs $34.5 \%$ birth order one. This finding was in line with the study conducted in Cambodia (Rathavuth \& vinod 2006). This might be due to family is unable to satisfy child dietary and other health care related services because of more numbers of children and might also be due to low awareness of family planning.

As regards to the birth interval of child it was observed that a significant difference between birth interval and degree of stunting $\quad(\mathrm{P}$ value $=$ $\left.0.025^{*}\right)$ this result agrees with (EDHS, 2011) who reported that, there is an inverse relationship between the length of the preceding birth interval and the proportion of children who are stunted. The longer interval, were less likely to be child was stunted.

(Central Statistical Agency [Ethiopia], 2011).

In the current study was noticed that there was significant difference between mother age and degree of nutritional stunting ( $\mathrm{P}$ value $=0.008^{*}$ ) This result agrees with study in Nepal, when maternal age at pregnancy was more than 40 years, there was 2.6 times risk of stunting in the children ( Onis et al., 2011).

This might be due to mothers with age 35 years being high risk for pregnancy and also resulted from poor nutritional status of them, they lack of awareness about the nutritional status during pregnant .

In this finding stunting was found not associated with mothers' educational level, but on the other hand, these results disagree with study in India that found 
stunting significantly associated with mothers' educational level (Malay, 2012).

From present study was observed that the availability of safe drinking water was not associated with the prevalence of stunting. This result agreed with study in Cambodia that revealed that availability of safe drinking water was not associated with prevalence of stunting (Peiris \& Wijesinghe 2010).

In Ethiopia it was observed that the prevalence of stunting among children of households with no protected water source was significantly higher as compared with those who have stunting (Ali 2010). The current finding revealed that there is no association between child length and weight at birth and the degree of stunting. These results disagree with study conducted in Ghana which indicated that children who were very small at birth had a higher probability to be stunted ( Rathavuth, 2006)

According to medical history of child the present finding of this study showed that children with recurrent worm and ear infection associated with stunting with significant differenc (P value $=0.046,0.001$, ) respectively. This might be due to malabsorption of nutrients and recurrent using of antibiotic in the treatment of infection

These finding were similar to (Japheth, 2010) that shows that stunting were $44.2 \%$ in the children with worms and ear infection.

Regarding child feeding practice, these result revealed that proportion of stunting among children whose mothers' initiated breast feeding one hour after delivery $33 \%$ less than $39.7 \%$,for whose mothers' initiated breast feeding more than one hour after delivery. This finding similar to study in India that showed the proportions of stunting among children whose mothers initiated breastfeeding within one hours $(49.6 \%)$ was significantly less $(\mathrm{P}<0.02)$ than that $(64.6 \%)$ for those whose mothers initiated breastfeeding after one hour (Malay, 2012). This might be due to breast feeding within one hour after delivery contain highly nutrients substances (colostrum)

Regarding duration of exclusive breast feeding observed that the

proportion of stunting is $40 \%$ in children whose exclusive breast.

Feeding more than six months. These finding similar to study in Cambodia (Peiris et al., 2010) with significantly higher prevalence of stunting (48.7\%) with children whose exclusive breast feeding more than six months. Regarding child feeding practice during and after period of illness, this finding showed that there is a significant difference between degree of stunting and child whose mothers discourage them to eat during period of illness and recovery $(\mathrm{P}$ value $=$ 0.000).This finding similar to study in India
(Ngianga, 2011) who indicated that the deprivation of feeding during illness and recovery period was high significance $(\mathrm{P}$ value $<0.001)$ for children under five years.

Also in the current study, it is observed that there is a significant difference between giving child junk food include sugary, salty foods and soft drink ( $\mathrm{P}$ value 0.002) this finding similar to studies which have demonstrated that obesity and stunting in children are associated with a decreased intake of nutrient-rich foods and an increased consumption of junk foods (i.e., nonnutritive processed foods, sugary drinks). This might due to junk foods can replace nutritious foods, which can lead to nutrient deficiencies and malnutrition (Food \& Agriculture Organization of the United Nations2006).

There is an evidence that improving growth through adequate and appropriate complementary feeding can have a significant effect on adult wages an evaluation of one program in Latin America that provided goodquality complementary food to infants, found that the wages of males in adulthood increased by $46 \%$ compared to peers who did not participate in the program (WHO, 2013).

\section{Conclusion}

Based on the result of the present study, it can be concluded that.

- Prevalence of nutritional stunting among children under five years was than thirty percent.

- The results showed that child age, age of mothers, birth interval, child birth order, residence, child feeding practice and medical history of child were the most significant factors influencing stunting of children. Growth restriction occurs primarily during the pre-natal period and first two years postpartum. Thus, targeted nutrition interventions should focus on these periods of life cycle, adequate maternal nutrition during pregnancy, optimal infant breast feeding, complementary feeding practices, and nutritional supplementation, when necessary, along with interventions for the prevention and appropriate treatment of infections.

\section{Recommendations}

- Based on the result of the present study, the following recommendations are suggested

- Increase awareness of mothers about nutritional stunting, monitoring growth \& development of child, and the benefits of early detection in treatment through mass media.

- Educational nutritional intervention for mothers that promotion and support infant and young child feeding practices with the most critical period (1000) days of child life and integrate the key of 
hygiene care , anational policy on junk food should be developed, stating that junk foods (are dangerous) should not be given to children less than 2 years of age and junk foods should not be marketed to young children.

- Aguid book should be distributed to all mothers with stunting and non-stunting children to improve their knowledge .

\section{References}

1. Adair L., Fall C., Osmond C., (2013): Associations of linear growth and relative weight gain during early life with adult health and human capital in countries of low and middle income: findings from five birth cohort studies. Lancet; 382(9891):525-534.

2. Ali, M., (2010): The impact of feeding practices on prevalence of under nutrition among 6-59 months aged children in Khartoum. Sudanese journal of public health. 5(3).

3. Black R., Victora C., Walker S., Bhutta Z., Christian P., De Onis M., (2013): Maternal and child undernutrition and overweight in lowincome and middle-income countries. Lancet, 382(9890): p. 427451. Available at: http://dx.doi.org/10.1016/S0140-6736 (13)60937-X.

4. Central Statistical Agency [Ethiopia] \& ICF International, (2011): Ethiopia Demographic and Health Survey 2011. Addis Ababa, Ethiopia and Calverton, Maryland, USA: Central Statistical Agency and ICF International

5. De Onis M., Blossner M., \& Borghi E., (2010): "Prevalence and trends of stunting among preschool children", Public Health Nutrition, Vol (92). PP 1257-1264.

6. Deonis M., Blossner M., Borghi E., (2011): Methodology for estimating national and global trend child under nutrition, pp. 1260-1270.

7. Deshmukh P., Sinha N., Dongre A., (2013): Social determinants of stunting in rural area of Wardha, Central India. Med J Armed Forces India. 69(3):213-7.

8. Egypt Demographic \& Health Survey, stunting rate highly and have large remained static, EDHS (2011).

9. Egyptian Cabinet Information \& Decision Support Center (IDSC), (2013): World Food Programme . Cost of Hunger in Egypt: Implications of Child Undernutrition on the social and Economic Development in Egypt. The Social and Economic Impact of Child Undernutrition in Egypt. Cairo, Egypt : World Food Programme.

10. El-shafy A., Ibrahim K., Ahmed S., \&Mohammed N., (2013): Mother's Knowledge and Attitude Regarding Acute Diarrhea Disease at Assiut Children's Hospital, AJN. 28(9), 15-25.

11. Food \& Agriculture Organization (FAO) of the United Nations (2008): The double burden of malnutrition: Case studies from six developing countries, Vol (132). PP 120-126.

12. Food \& Agriculture Organization (FAO) of the United Nations (2008): The double burden of malnutrition: Case studies from six developing countries

13. Happiness, S., (2010): Persistent child malnutrition in Tanzania. Risks associated with traditional complementary foods (A review). African Journal of Food Science, 4(11):679-692.

14. Japheth. A., (2010): Pediatric Diarrhea in Southern Ghana: Etiology and Association with Intestinal Inflammation and Malnutrition, Am. J. Trop. Med. Hyg., 83(4), pp. 936-943.

15. Jesmin A., Malik A., \& Haque M., (2011): Prevalence and determinates of chronic malnutrition among preschool children, 29 (5) 494-9.

16. Kikafunda J., Walker A., Collett D., Tumwine J., (2010): Risk factors for early childhood malnutrition in Uganda. Pediatrics. 102(4).

17. Mahfouz E., Mostafa S., Sadek R., Hathout M., AwadAllah H., (2003): Rural/Urban infant nutrition gaps and KAP Of mothers in El Minia and Giza governorate, Egypt. The Egyptian Journal of Community Medicine. 21 (1): 17-24.

18. Malay K., (2012): Acceptability of Lipid-Based Nutrient Supplements and Micronutrient Powders among Pregnant and Lactating Women and Infants and Young Children in Bangladesh and their Perceptions about Malnutrition and Nutrient Supplements, FANTA-2, FHI 360.

19. Ngianga. B., (2011): Malnutrition among children under the age of five in the Democratic Republic of Congo (DRC): does geographic location matter?. BMC Public Health, 11:261.

20. Nutritional Status of the Egyptian Population in Egypt, (2010): Egypt Demographic and Health Survey, 2008, PP1-81.

21. Prendergast A., \& Kelly P., (2012): Enteropathies in the developing world: neglected effects on global health. The American Journal of Tropical Medicine and Hygiene86, 756-763.

22. Peiris \& Wijesinghe (2010): Nutritional Status of under 5 Year-Old Children and its Relationship with Maternal Nutrition Knowledge in Weeraketiya DS division of Sri Lanka. Tropical Agricultural Research Vol. 21(4): 330 339

23. Rahman A., Chowdhury S., (2007): Determinants of chronic malnutrition among 
preschool children in Bangladesh. J Biosoc Sci . 39:161-73.

24. Rathavuth. H., Vinod. M., (2006): Effect of Wealth Inequality on Chronic Under-nutrition in Cambodian Children, J HEALTH POPUL NUTR, 24(1):89-99 FAO.

25. Teshome, B., (2009): Magnitude and determinants of stunting in children under five years of age in food surplus region of Ethiopia: The case of West Gojam Zone. Ethiop.J.Health Dev; 23(2):98-106.

26. United Nations Children's Fund, (2013): UNICEF Global Approach to Scaling up Nutrition Programming, UNICEF, New York, 2013

27. USAID, WHO, (2015): The Behavior Change Framework: A Template for Accelerating the Impact of Behavior Change in USAID supported Ending Preventable Child and Maternal Deaths (EPCMD) Programs in 24 Priority Countries. Vol 2, No 1, Pp1-3.

28. Victora C., de O., Hallal P., Blossner M., \& Shrimpton R., (2010): Worldwide timing of growth faltering: revisiting implications for interventions. Pediatrics. 125(3):473-480.

29. World Health Organization (WHO), (2013): Stunting Policy Brief. WHO Globel Nutrition Target. vol. 378, no. 9799, pp. 1325-1338

30. World Health Organization (WHO), (2013): Maternal, infant and young child nutrition in sixty fifth World Health Assembly, Geneva, 2126 May. Resolution and Decisions Annexes, Geneva. 